\title{
THE SEMIOTICS OF THE FACE IN DIGITAL DATING: A RESEARCH DIRECTION
}

\author{
Massimo Leone \\ University of Turin, Italy \\ Shanghai University, China \\ massimo.leone@unito.it
}

"She's not wearing makeup so her face just looks like skin."

(Chuck Palahniuk. 2011. Choke. New York, NY: Random House, p. 22)

\begin{abstract}
:
The article investigates the socio-cultural meaning of the face in relation to its natural and biological features, focusing on the particular domain of mating habits. After surveying the role of the 'face' in the sexual behaviors of several non-human animals, and especially of primates, the article ponders on the crucial role that the face plays in the seductive discourse which precedes and accompany mating in all human cultures and also in many primates' behaviors. It, then, deals with the transformation that these seductive patterns of signification and communication undergo in the passage from face-to-face intercourse to digital dating. Here, the gap between the necessarily realistic representation of one's bodily face and the idealized version of it allowed by digital picture editing widens, to the point that new epistemic parameters start to circulate throughout the digital semiosphere.
\end{abstract}

This project has received funding from the European Research Council (ERC) under the European Union's Horizon 2020 research and innovation programme (grant agreement No 819649 - FACETS). 
Keywords: face, semiotics, seductive discourse, primates, digital dating

\section{Introduction: the semiotics of the face}

The face is omnipresent. Every human being has a face. Since birth, it is displayed and seen as an interface. Invisible beliefs, emotions, and intentions become visible on the face. Some of its features cannot be controlled: blushing, for instance, betrays the face. Most of the face, however, can be altered. People change the color of their skin, the shape of their hair, display emotions that they do not have, lie, to the others or even to themselves. Individuals use their face to communicate but they are not alone. Patterns of face signification become part of history, tradition, and culture. They are deposited in the collective memory and become common sense. That is why the human face is one in nature but multiplies in cultures. Each society, and each epoch, develops face trends. The biology of the face meets the semiology of a specific human group and becomes custom, as well as second nature. Smiling, for instance, is an adaptive human behavior, selected by natural evolution for its capacity of signaling the intention not to attack an interlocutor (Graziano 2009 , ch. 12). Yet, each culture smiles in a different way, ${ }^{1}$ although these smiling habits may become spontaneous, unmediated second nature.

Face cultures are composed not only of actual human faces but also of their representations through different media. Descriptions of faces in words, images, and other signs circulate through society, become viral, turn into models, and affect the ways in which people use their faces. The human propensity to represent the face is ancient. Pliny the Elder sets the mythical beginning of the portrait in a loving girl's desire to preserve the silhouette of a leaving beloved (Naturalis Historia, XXXV, 15). Yet, face cultures change in time and space also depending on the available technology of face representation. When Pliny the Elder was alive, remembering the face of a distant beloved could rely on a limited array of signs. The funerary mask was the only indexical representation of a face until the invention of photography.

With photography, a link was created between the ontology of a face and its representation. This representation, however, was also a reproduction:

\footnotetext{
${ }^{1}$ For a comparative survey of smiling across cultures, see Waltraud 2008; see also Trumble 2004; for an early classic on the philosophy of smiling, see Vasey 1877. There are several semiotic contributions on humor but few on smiling; see Glazer 2017 on a Peircean approach to the semiotics of expressing emotions; an early attempt at reconsidering Darwin's classic Expressions of the Emotions in Man and Animals (New York, NY: Appleton, 1897) is to be found in kinesics, for instance in Birdwhistell 1971: 541-8. A recent experiment shows that the possession and usage of smartphones is decreasing the human habit of smiling to strangers (Kushlev et al. 2019); on the semiotics of smiling through emojis, see Danesi 2016.
} 
the photographed face was truly an icon of the original, yet it was also disquietingly replicable, like a symbol. The uncanny character of these face representations deepens with the advent of digital technology. On the one hand, the realism of pixel representations of the face is unprecedented. On the other hand, the arbitrariness of these pixels introduces a paradoxical anxiety: pictures of the face are now extremely believable and extremely untrustworthy at the same time.

\section{Facing mates}

The availability of digital technology is introducing new trends in face cultures around the world (Leone 2017). At the same time, long period ideological shifts are finding expression in these trends. Since immemorial time, the face is also used as an interface to trigger desire in potential mates. Most mammals, including most primates, mate in what is technically called the dorso-ventral position, with both animals facing in the same direction; among primates, only the hyper-sexual bonobos and, more rarely, gorillas copulate in ventro-ventral mating positions (Fig. 1).

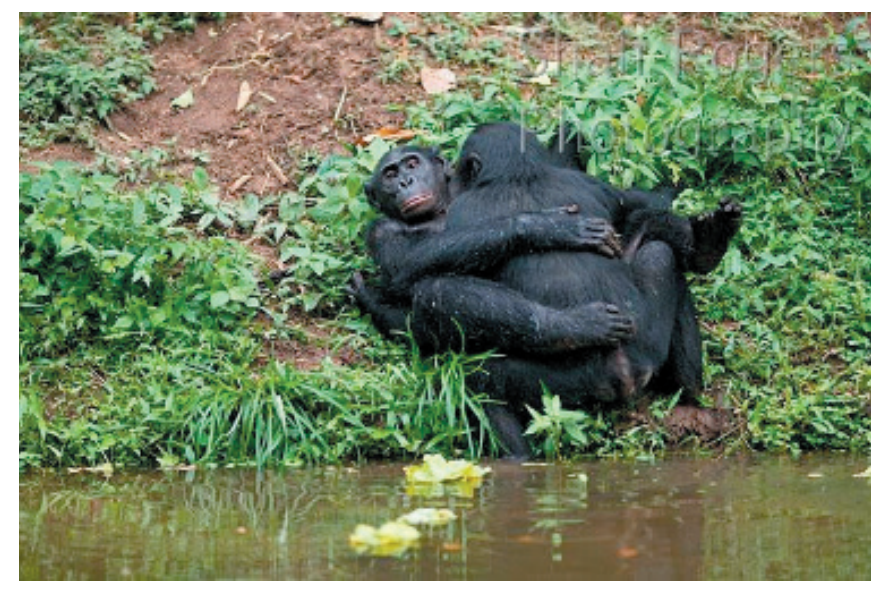

Fig. 1: Bonobos mating face to face (Pan paniscus). Lola Ya Bonobo Santuary, Democratic Republic of Congo, October 2010 (Copyright: Anup Shah, 2011).

Even primates adopting the dorso-ventral position, however, use the face in order to attract a potential mate (Dixson 2012: 133). Female 'seductive' facial expressions seem to be specific of the species: patas monkey, for instance, puff out cheek pouches and drool; common marmosets, Cottontop tamarins, and Goeldi's monkeys protrude their tongues rhythmically (Fig. 2); howler monkeys display 'tongue-pumping' (Fig. 3); chacma baboons 
put on an 'eye-face', with raised eyebrows and flattened ears (Fig. 4); capuchins grimace and raise their eyebrows (Fig. 5); many langurs, leaf monkeys, doucs, and proboscis monkeys perform rapid lateral head-shakes; white-throated capuchins put on a 'duck face' by protruding their lips.

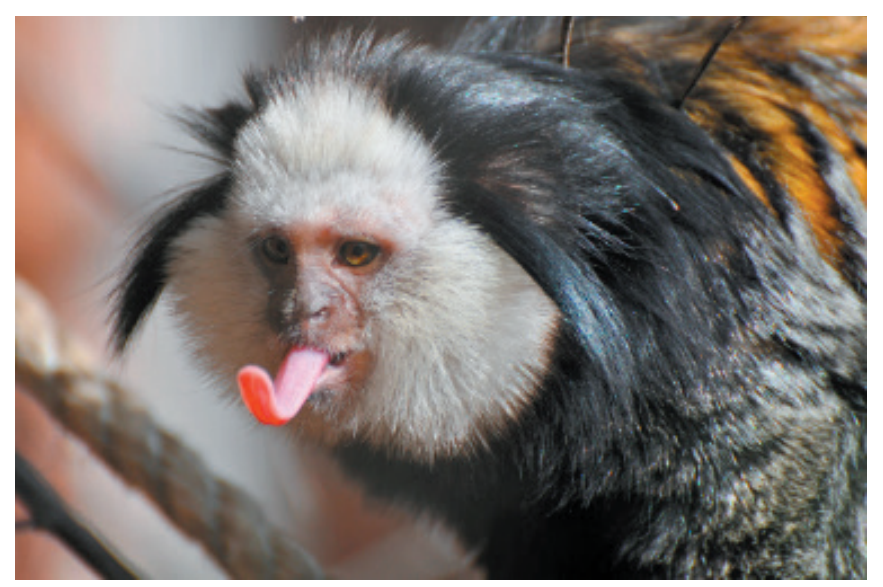

Fig. 2: Common marmoset protruding its tongue as part of mating behavior (copyright: Alchetron.com).

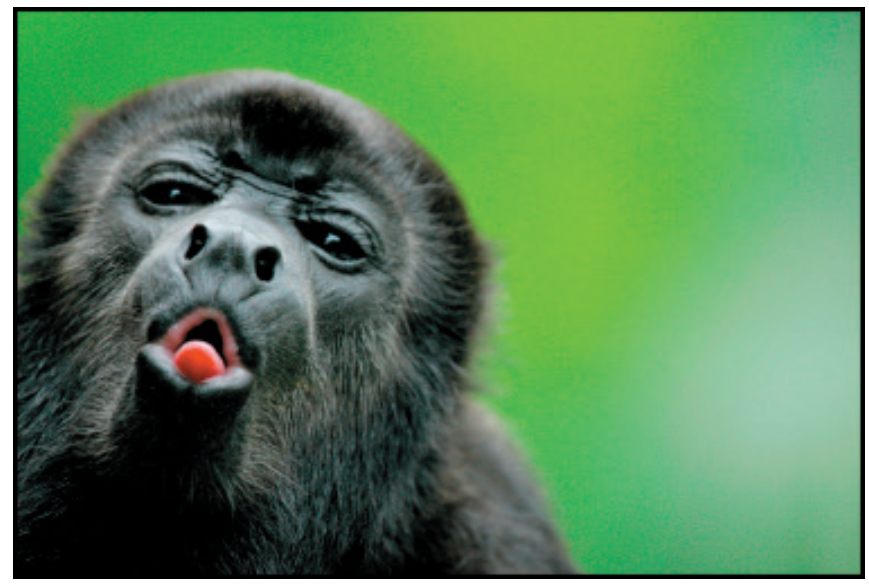

Fig. 3: Howler monkey displays 'tongue-pumping' as part of mating behavior (copyright: http://www.rofindustries.com). 


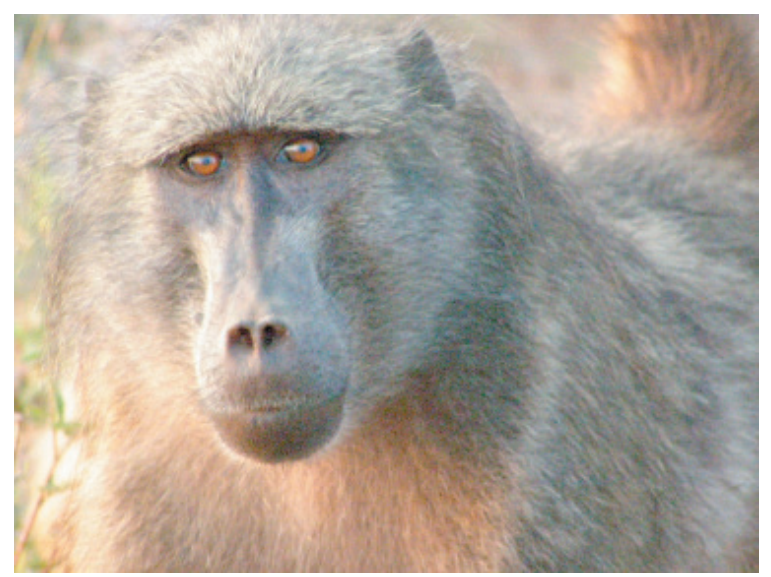

Fig. 4: Chacma baboon putting on an 'eye-face" as part of mating behavior (copyright: shallicomparethee.wordpress.com).

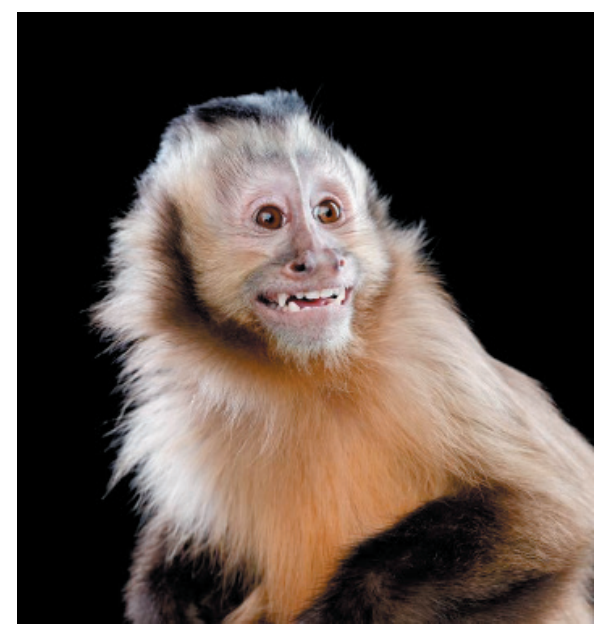

Fig. 5: Brown capuchin grimaces and raises its eyebrows as part of mating behavior (photograph by Brad Wilson; copyright: Stone/Getty Images).

In many primates, moreover, including humans, eye-contact with the male is adopted as a seductive facial strategy. Common marmosets, Goeldi's monkeys, squirrel monkeys, brown and white-throated capuchins, black and woolly spider monkeys, up to orangutans, gorillas, chimpanzees, and bonobos: the females of all these species try to look the male into its eyes when they want to mate (Fig. 6). Most specialists, though, seem to agree on the fact that smiling, embracing, and kissing are systematic displays of mating intentions only in the human species. 


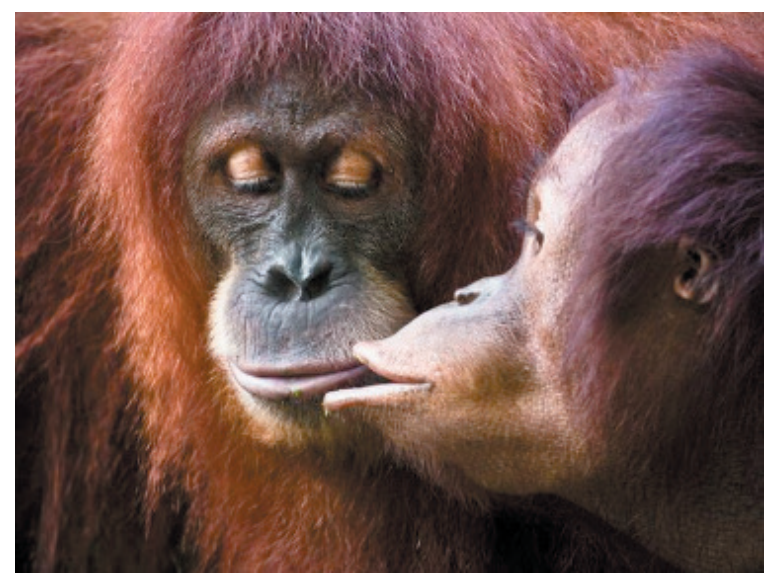

Fig. 6: Orangutans seeking eye-contact as part of mating behavior (copyright: FunMag).

In Asian and African species of primates, different facial mating behaviors have evolved, whereas eye-contact proceptivity seems to appear in all anthropoid females, usually with increase in frequency during the peri-ovulatory phase of the ovarian cycle. Also in humans, seeking eye-contact and raising eyebrows seem to be transcultural features, related to the central role of the synchronization of facial expressions in establishing potential mating relations (Dixson 2012).

\section{The face as communicative project}

The propensity to alter the appearance of one's face through artificial adornments can be observed in non-human species too. Specific studies, for instance, have demonstrated that a new adorning behavior can emerge in chimpanzees, such as selecting a stiff, straw-like blade of grass, inserting it into one ear, adjusting the position, and then leaving it in there during subsequent activities (Fig. 7) (Van Leeuwen, Cronin, and Haun 2014). Moreover, the same studies have shown that these adornments behaviors can spread among other members of the same group, establishing a sort of fashion trend. These ethological observations indicate that chimpanzees spontaneously copy arbitrary adornment behaviors from their group members.

Creating visual representations of faces is rarely seen in non-human species and is usually a behavior that results from human instruction (Morris 1962), such in the case of elephants painting other elephants in Australia or Thailand (Fig. 8). 


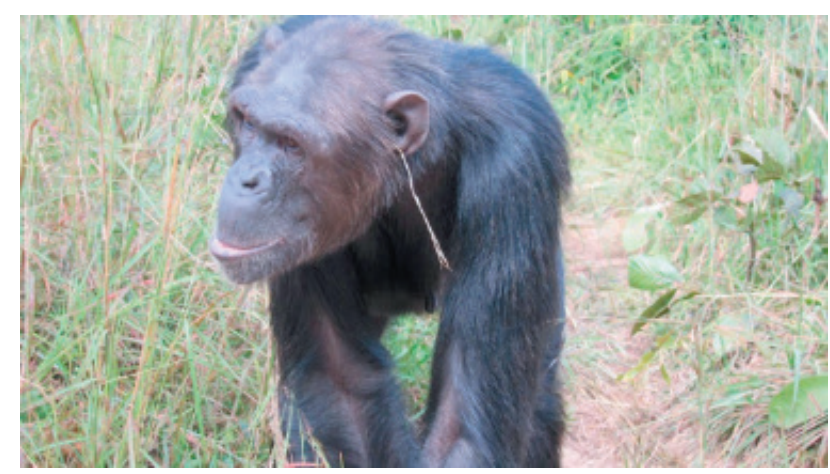

Fig. 7: Chimpanzee "Julie" putting a stiff, straw-like blade of grass in one or both of her ears (copyright: Van Leeuwen, Cronin, and Haun 2014).

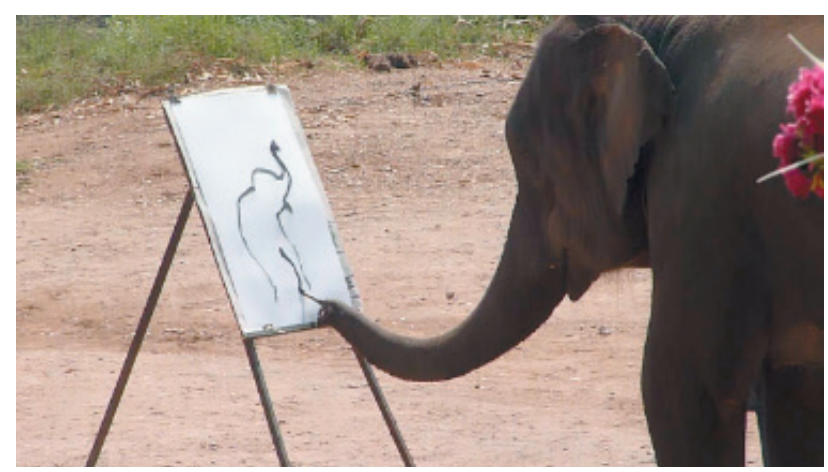

Fig. 8: A trained elephant painting in Chiang Mai, Thailand.

An interesting case, then, is that of animals that accidentally take photographic self-portraits of themselves, such as that taken by an elephant in May 2015 in Koh Phangan, Thailand, with the GoPro Camera of a tourist (Fig. 9). 


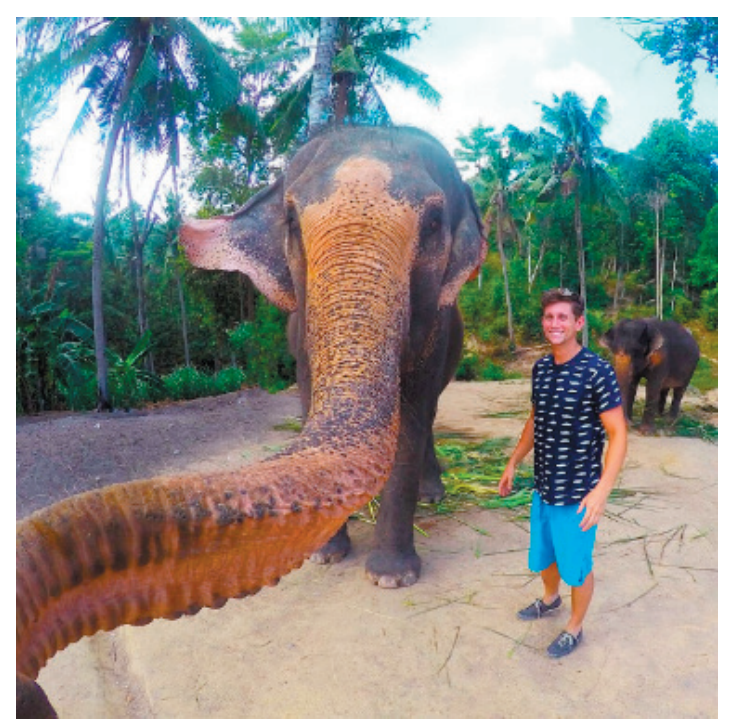

Fig. 9: Accidental self-portrait by an elephant with photo taken with the GoPro camera of Christian Le Blanc in Koh Phangan, Thailand.

Increase in this kind of representations, however, is certainly not due to changes in animal cognition but to the statistics of accidental encounters between non-human animals and digital devices of visual representation. As Christian Le Blanc, the owner of the camera, reported to the BBC: "I quickly ran out of bananas and the elephant swiftly reached for my GoPro camera. Luckily it was on a continuous filming setting so the whole thing was captured" (https://www.bbc.com/news/blogs-trending-32848199).

One of these cases became famous worldwide since it also resulted into a legal dispute, the so-called "monkey selfie copyright dispute". In mid2011, a Celebes crested macaque in Tangkoko Nature Reserve in Indonesia 'used' equipment owned by nature photographer David Slater so as to take a series of self-portraits, including one that became world-famous. The dispute involved Wikimedia Commons and the blog Techdirt, which had hosted the images following their publication in newspapers in July 2011 over Slater's objections, and People for the Ethical Treatment of Animals (PETA), who argued that the macaque should have been assigned the photographs' copyright (Fig. 10).

The question of the possibility that a non-human agency might create visual and even artistic representations was already raised by Cicero in De Divinatione $(\mathrm{I}, 13,23)$, his treatise on divination, precisely through the example of a sow being able to trace the letter " $A$ " on the ground with its snout. Cicero argued that such accidental accomplishments could not give rise to the complexity of the human-made arts, concluding that the agency of nature 


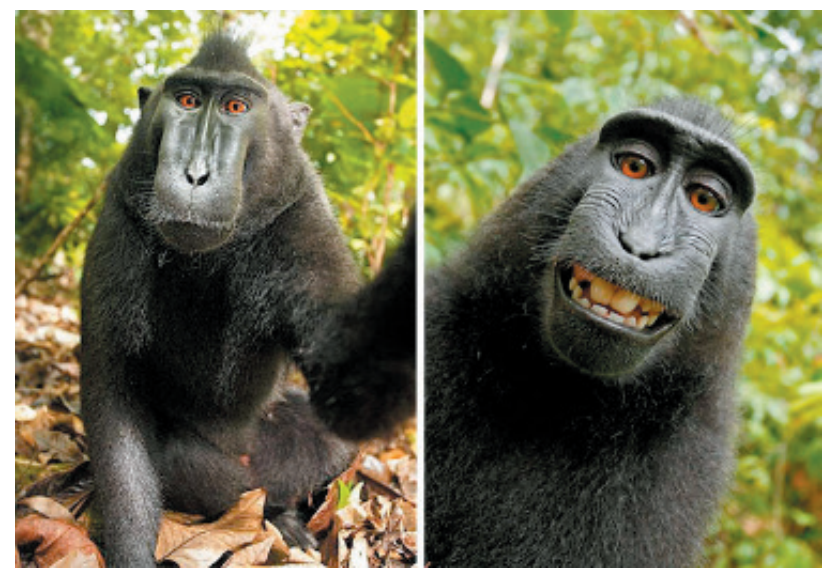

Fig. 10: Accidental "selfies" taken by Celebes crested macaque in Tangkoko Nature Reserve in Indonesia (copyright: creative commons).

is inferior, in this domain, to that of the artist (Leone 2016). The pseudo-self-portrait taken by the macaque, however, is interesting from another point of view. Although it is quite evident that it is not an intentional selfie but an accidental self-portrait, the intentio operis of this visual text, that is, the way in which its gestalt is arranged, is such that it is quite natural to take it for a selfie. In the first of the pictures, the macaque shows what appears as a neutral, concentrated expression to the camera, as though it was intent upon setting it; the contiguity between its left paw and the photographic device is well visible in the left side of the image, suggesting the indexical nature of the visual representation: the macaque ontologically was in front of the camera when the photograph was taken. The selfie illusion, however, is triggered by the dialectics between the first picture and the second, where the macaque appears as posing and smiling in front of the camera as though it was really satisfied to be about to leave a jolly photographic image of its face to posterity.

This anecdote shows, on the one hand, that human beings are the only species thus far that systematically represents its own face, through media that have considerably evolved throughout the history of communication technology, with significant cultural consequences. On the other hand, the anecdote also points out that an existential and ontological incertitude is intrinsic to the human practice of face visual representation: the more the technical potentialities for visually rendering the face improve, the more the suspect of their artificiality increases. It is quite probable that the 'selfie' of the macaque does not correspond to any intention of face self-representation; but is the status of the myriad of face digital icons that circulate through the web much more certain? 


\section{The face in digital dating}

That is a crucial question in the domain of digital dating. ${ }^{2}$ There is a feature that seems to characterize the behavior of the face in the mating habits of all human cultures, and that is characteristically present in many non-human species as well, such as in primates, for instance. Especially in the phase that precedes sexual intercourse, each of the mates seeks to attract, retain, and seduce the attention of the others through modifying the appearance of the face in a peculiar and specific way, which is codified by both nature and culture. The ductile mobility of facial musculature in mammals, and especially in primates, enables the emergence of expressive configurations that take shape only in concomitance with specific biological circumstances, such as the peri-ovulatory phase in female mammals, or in specific cultural circumstances, such as the gathering of a large number of males and females of the human species in a nightclub.

A structural approach is sufficient to underline that the face both in primates and in humans entails the possibility to differentiate between a mating and a non-mating expression. The question remains to determine whether such difference is also such to develop a semiotic potential: if, according to Eco's famous witty definition, semiotics is the discipline that studies everything that can be used to lie or, more abstractedly, everything that has an alternative, then in order for the facial behavior of a mate to turn into an object of semiotics, such behavior should not be only compulsorily linked to natural instinct but also somehow shaped by cultural patterns and individual choices.

In humans, there is little doubt that codified facial expressions, including those used to enhance sexual attractiveness, can be faked. One can actively look for eye-contact with someone one is not actually sexually interested in, in order to simulate such interest. With the exception of blushing and other reflexes, everything in the face becomes a matter of alternative and, therefore, choice. That is not tantamount to affirm that individuals

\footnotetext{
2 The bibliography on Internet social dating is still scattered, fragmentary, and characterized by plenty of grey literature. Interesting contributions are Wang and Alasuutari 2017, which studies the role of digital social dating in the touristy experience; Ward 2017 (on impression management); Ayalon and Gewirtz-Meydan 2017 (a qualitative analysis of adult dating sites); Toma 2017, which specifically deals with deceptive communication in digital social dating (on authenticity in Tinder, see also Duguay 2017); on the Muslim world, Sotoudeh, Friedland, and Afary 2017; on LGB digital dating, Johnson, Vilceanu, and Pontes 2017, and on differences between gay and lesbian digital environments, Tang 2017; on sexting, Van Ouytsel et al. 2017; on WeChat in China, Xue et al. 2017; on anonymity in digital dating, Blacka, Mezzinab, and Thompsona 2016.
} 
consciously decide how each and every aspect of their face shows at every moment. The degree of care and consciousness by which a face is prepared to communicate to the world depends on a number of contextual circumstances. A TV-news anchorman daily showing his face to millions of spectators - thus embodying, through it, the system of values behind a TV channel or program - will probably be maniacally attentive to the way in which each feature of the face means something. On the contrary, the miner who is going to work all day protected by a helmet, his face invisible beneath it, will probably pay very little attention to the look of his face.

In some sociocultural contexts, however, nature and culture 'conspire' so as to attribute an enormous emphasis to the face. The domain of sexual encounter is certainly one of the most sensitive ones. In primates as well as in humans, the face works as a central interface in order to seek to establish a sexual relation. As it was pointed out earlier, non-human animals use their face to 'seduce' but cannot rely to representations of the face. That is, on the contrary, a prerogative of humans, which finds expression in several cultures.

On the one hand, the human face itself is turned into a representation having itself as a support. That is evident in the activity that goes under the name of make-up; ${ }^{3}$ make-up does not limit itself to change the appearance of a face but uses the natural face - although a zero degree of it cannot be really conceived, since it is always the result of a cultural transformation as a sort of canvas for the visual representation of a second face. The natural face, or at least that which is less culturally conditioned or conditioned by factors that escape the control of the individual, is superimposed with a cultural face that transforms the former according to a strategy of communication and, often, seduction.

Putting lipstick on can be a spontaneous habit, yet it conveys at least the project of signification that a culture imposes on a face through such lipstick. The more a social occasion is important, the more the face will be under evaluation, and the more lipstick will be chosen with sheer attention to its semiotic potential. In these cases, then, lipstick becomes the visual device through which a facial text is superimposed on its facial support. Such text, which simply results from the application of color on a subject's lips, contains an individual intentio auctoris, that is, an intent to communicate something through such application, but inevitably gives rise to an intentio lectoris, that is, to the interpretation of a spectator, which might be strikingly at odds with

\footnotetext{
${ }^{3}$ The literature on the topic is abundant. Among the most recent relevant contributions, see Stewart 2017; among the recent semiotic studies on the subject, see Mathé 2010, Ellison 2014, Ogilvie 2015.
} 
the former. That which determines the appropriateness of lipstick semiosis in a given social and cultural context is its intentio operis, that is, the visual common sense that a community shares around such facial transformation.

That does not mean that putting lipstick on is immediately conducive to a form of social lie; that is not the case for, as it has been underlined earlier, a face without lipstick is not a zero degree of communication but a communication project itself, whose effects depend on the dialectics with the presence of facial make-up. It is not difficult to understand that one can lie about one's invisible beliefs, emotions, and intentions not only through changing one's face appearance but also through omitting to change it. A girl can fake an inner status of purity and innocence, a "water and soap" ["acqua e sapone"] look, as Italians say, exactly through abstaining from make-up, an abstinence that can be as intentional and communicative as its positive counterpart.

\section{Lies we live by}

To recapitulate, no matter what we do, our face becomes the bodily support of a facial text that tells a story about us, a story that can be totally fake, it can be perceived as in line with our inner self, but in most cases is 'a lie we live by', an image of ourselves that seems appropriate to us in a certain phase of our life and that we identify with as our most appropriate facial and visual "we". In complex societies, the human face can be modified in so many ways that mastering the signs that attribute a certain meaning to the facial support of face communication can become a challenge. That is so also because competence about the more or less cogent codes that determine the meaning of a textual face are not equally distributed in a society and are subject to a vast and intricate arrays of codes, microcodes, and even undercodes.

For instance, a girl might distractedly put on a certain kind of lipstick but this might be interpreted by her job interviewer as a sign of shallowness or even shabbiness and lack of distinction; conversely, lack of lipstick can be interpreted by a potential mate as the reassuring sign of a sexually sober personality or, on the opposite, as the stigma of someone lacking sexual drive. The final semiotic outcome of the facial text will result from the encounter (or the clash) between a communicative proposal, be it totally intentional or not, and an interpretive attitude, be it conscious or not, mediated through an intentio operis of 'shared facial common sense' that, nevertheless, becomes increasingly thinner in complex societies and tends to disintegrate in the post-modern ones.

The face is, therefore, a technology of communication whose hardware we are endowed with by nature since birth but whose software is heavily subject to sociocultural variation, to the point that this variation reduces 
more and more the autonomy of the hardware itself. Conceiving the face as a technology of communication, which can be also used for seductive purposes, implies two symmetric advantages: on the one hand, it leads to a comparative sphere (Branco, Mohr and Leone 2018): smiling or sending an emoji through a smartphone seem to be two completely different activities, with the latter being simply the digital mimicry of the former; yet, from a semiotic point of view, a smile is no less a communicative project than an emoji. Although the first seems to be more closely related to the biology of the body than the second, it too functions as a sticker superimposed on the physical face so as to transform it into a semiotic one.

On the other hand, conceiving the face as a technology of communication leads to a contrastive view: there is not only a quantitative but also a qualitative difference between the ape that seduces by moving its facial muscles in a certain way, the human that seeks to attract a potential partner by putting make-up on, and the individual that looks for potential mates through adopting a digital avatar. The three are technologies of communication and seduction, yet they imply an increasing semiotic potential, which entails in turn an increasing possibility to nuance the communication, an increasing capability for lying, and the production of an increasing ontological incertitude.

\section{Semiotic leverage and ontological incertitude}

An example will clarify this 'escalation in semiosis'. Many human beings are born with moles or birthmarks, that is, little spots on the skin that are pigmented more than the surrounding areas. There are different kinds of moles and birthmarks but, up to a certain stage in the history of the western civilization, they have been considered as part of the natural appearance of a face or body. That is true to such an extent that in many civilizations, birthmarks have been linked to a supernatural dimension, completely out of the reach of human influence. ${ }^{4}$ On the one hand, thus, medical semiotics treats moles as signifiers that indicate the possible presence of skin cancer when their visual configuration is modified in a specific way. Dermatologists can learn and master the code that allows them to infer, from the visual inspection of color, shape, size and texture of moles, the possibility that the patient who manifests them might be developing a melanoma. On the other hand, cultural semiotics can study the interpretive schemes through which birthmarks, in a community of observers, are read as sources for narrative hermeneutics, as is traditional in many languages: called "voglie" in Italian and "alwahamat" in Arabic [i.e., "wishes"], their color and, sometimes, even their texture would

\footnotetext{
${ }^{4}$ On the presumed link between birthmarks and reincarnation, see Stevenson 1997.
} 
originate in the unsatisfied desire of a pregnant mother towards an object with the same visual qualities, normally food.

The cultural semiotician, however, must work hand in hand with the visual anthropologist in order to try to determine the broad ethnological scenarios in which the moles mean what they mean. Called "moedervlekken" in Dutch, "modermærke" in Danish, and "Muttermal" in German, birthmarks refer to a semiotic ideology according to which their epidermal imperfection, but also their potential as identity markers, derives from the mother, not from the father. In other cultures, such as the Iranian one, the origin of this imperfection and identity of the skin is not seen as related to a human source but as linked with a human agency in relation to a cosmological event: it is believed that birthmarks are caused by the fact that the mother has looked at the moon during an eclipse, touching her belly at the same time (that is why birthmarks in Farsi are called "maah gerefti", "lunar eclipses"). In other cultural contexts, such as the Ethiopian one, a birthmark is considered to derive from "a kiss from the Holy Virgin". Cultural semiotics and cultural anthropology can and should investigate how these interpretations are based on more general and comprehensive semiotic ideologies about the meaning of corporal imperfections, although these ideologies are often invisible and surreptitious.

Belief in the natural or preternatural origin of moles and birthmarks, however, is supplanted, at least from the seventeenth century on, by the idea that moles can become a language through which human beings, and especially women, can communicate something about themselves and, as a consequence, lie. The trend of drawing fake moles, or even to apply fake moles on the face, spreads throughout Europe, first in France ${ }^{5}$ (Fig. 11), then also elsewhere, and soon gives rise to a specific code, in which the position of the fake mole on the woman's face signals her sentimental attitude.

\footnotetext{
${ }^{5}$ See "La faseuse de mouches" ["the woman who makes fake moles"], anonymous text appeared in 1661 in the Recueil de pièces en prose les plus agreables de ce temps, composées par divers autheurs [sic]. Paris: Ch. Sercy: 54-63; Petitot 2015 is a brief but informative text on the topic.
} 


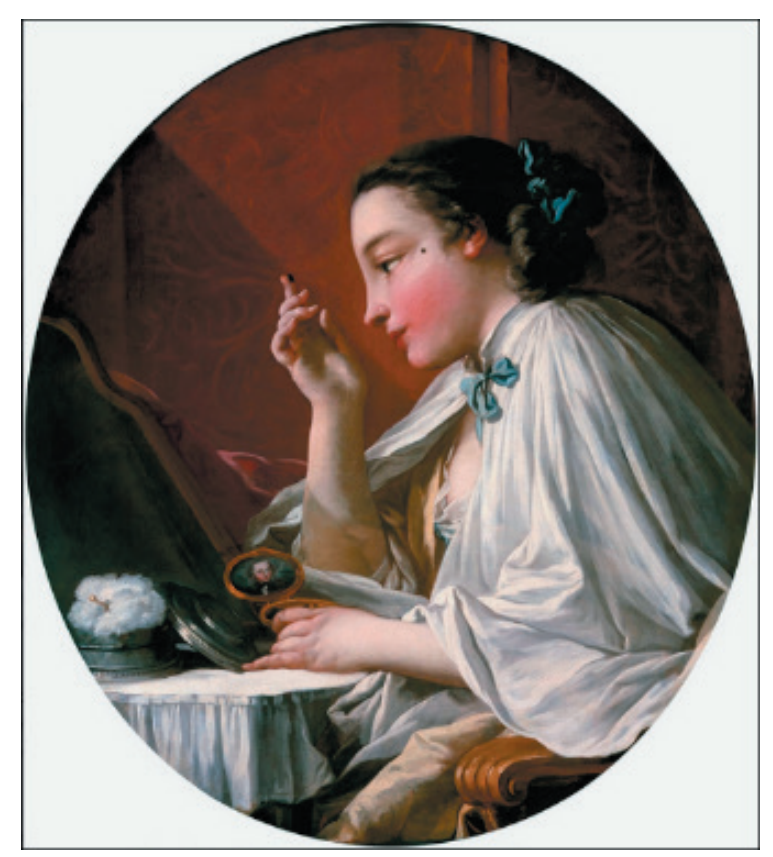

Fig. 11: François Boucher. 1738. La Mouche ou Une dame à sa toilette. Oil on canvas. $86,3 \times 76,2 \mathrm{~cm}$. Private collection.

In Peirce's terms, from the point of view of medical semiotics, a mole holds an indexical relation with its object, that is, a certain health condition of the skin. In this framework, moles can neither lie nor become the object of a proper semiotics either. Human beings cannot, through an actual mole, fake a skin cancer that they do not have and, once a mole manifests such health condition, unfortunately there is no way to fake the contrary, unless the mole itself is covered or altered through make up. When moles are singled out as fashion items, however, and given the availability of the communication technology that is necessary to fake them, from a simple pencil to actual prosthetic moles (Fig. 12), they cease to be indexical signs and turn into iconic signs, that is, into representamens that look like moles, which hold a relation of resemblance with moles. 


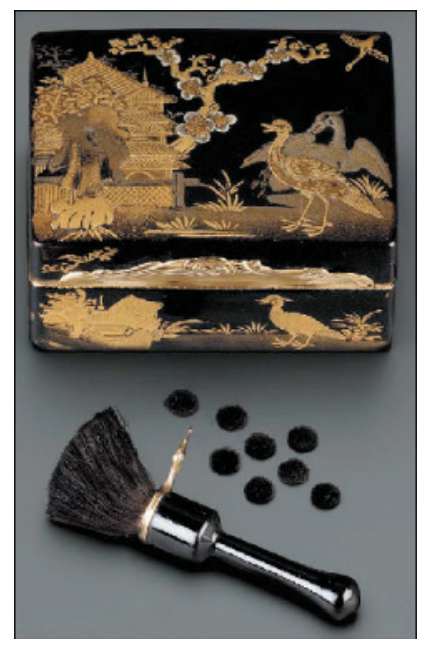

Fig. 12: $18^{\text {th }}$-century fake moles case, private collection.

Up to a certain extent, indexical moles cannot lie, although they can become the center of a fake narrative, as in legends about the origin of birthmarks, for instance. Iconic moles, on the contrary, are constitutively a lie, although the lie might stretch from a minimum, like visually fattening an existing mole, to a maximum, like sticking a completely fake and three-dimensional mole on the skin. Finally, this communication through moles may also give rise to a code that pairs certain types of moles and their position on the skin to certain conventional indications about the sentimental attitude of their holder (Fig. 13).

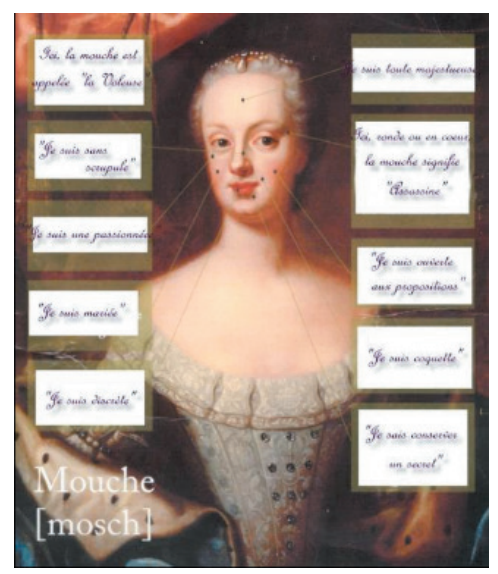

Fig. 13: The code of moles in $17^{\text {th }}$-century France (source: http://poudreemasquee.e-monsite.com/pages/historique/le-langage-des-mouches.html; last accessed 5 October 2018). 
It is important to stress, however, that the institution of iconic and symbolical moles retroacts on the semiotic nature of indexical moles as well. As regards the emergence of iconic moles, it leads to the necessity of developing a meta-code so as to distinguish between true and fake moles. Such meta-code enters a hide-and-seek relation with the code that is used to artificially creating moles, exactly like methods to fake artworks are in a dialectic and spiraling relation with methods used to reveal the fake. ${ }^{6}$ As regards the emergence of symbolic moles, it leads to the impossibility not to signify through one's moles, be they true or not. As long as their symbolical code is present in a community of interpreters, a mole is going to signify according to such code independently from the communicative intentions of its beholder.

\section{Digital moles and other everyday 'lies'}

The degree of epistemic uncertainty and ambiguity involved by facial communication increases accordingly in the passage from indexical signs to iconic signs, and from these to symbolical signs. It increases even more, however, when the entire face is represented through a visual artifact. A mole, as well as whatever other form of make up, is a technology of communication that can be used to convey more or less truthful meaning about the invisible qualities of a subject, yet such technology is still linked to its indexical origin, or at least to the indexical relation with the face. A mole can be faked, for instance, but lying through the face on which the mole appears would require a very complex operation, involving plastic surgery, for example. In general, the more the technology required to alter a certain aspect of the face is costly in terms of time, money, and risks involved, the more this aspect of the face will be considered as "natural" and immune from alteration. Through modern dentistry it is possible to whiten one's teeth and change their disposition and shape, yet completely transforming one's smile requires risky surgical operations, with the consequence that the shape of someone's smile seems to us more a sign of authenticity than the color of this someone's teeth.

Also the history of human representations of the face shows a similar evolution of the degree of liberty involved, together with its dialectics with the degree of epistemic uncertainty entailed. Such dialectics revolves around two polar existential needs: on the one hand, the representation of the face must be realistic, meaning that it must have an iconic or even an indexical relation with the face; on the other hand, the representation of

\footnotetext{
${ }^{6}$ Such as Morelli's method, whose semiotic relevance has been famously underlined by Carlo Ginzburg.
} 
the face must be idealistic, meaning that it must have a symbolic relation no longer only with the face but also with the prevailing values and ideals that are likely to affect the reception of the face image in a certain context. The two needs are sometimes matching: having a beautiful face means having a face whose symbolical connotations are those required in the frame of a particular communicative exchange; in such case, the representation of the face can be realistic and idealistic at the same time; Scarlett Johansson's face must not be idealized in its representations because it is already somehow ideal in itself in the context in which it is meant to appear and be represented (Fig. 14).

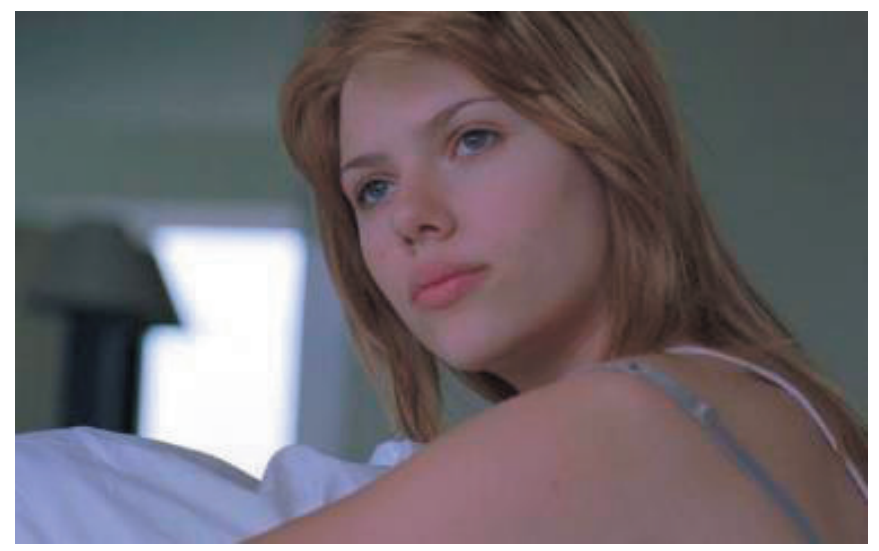

Fig. 14: Scarlett Johansson in Lost in Translation (Sophia Coppola, 2004).

One of the most semiotically interesting issues in the usage of the face in digital dating is that, on the one hand, digital images of the face must keep a significantly iconic or even indexical relation with the 'natural face' that they represent. This necessity is given by the fact that a real face-to-face encounter is usually the implicitly desired outcome of such digital representations and their usage, although the situation might be different in some contexts (for instance, digital dating social networks are increasingly used for other purposes, such as chatting out metropolitan night loneliness). In most cases, we want our digital pictures to resemble us at least to the extent that they enable their receivers to recognize us. At the same time, we want these digital pictures to idealize our face according to the aesthetic standards that are predominant in a certain communicative context. In a seductive context dominated by ageist biases, for instance, it is imperative that we look the right age required in order to potentially seduce the target of partners we have in mind. A woman in her forties wanting to seduce men 
in their thirties in the current western society, for instance, will be likely obliged to 'idealize' the digital image of her face accordingly.

\section{Conclusions}

The semantic and pragmatic field between realistic and idealistic representations of the face widens in digital imagery. On the one hand, the representation of the face can be altered in unprecedented ways; on the other hand, tolerance toward these alterations increases as well. Indeed, idealizations of the face must not go beyond that critical point that makes them look unrealistic; but how is this critical point determined? A series of coordinates set the critical threshold between recognition of resemblance and realization of fake. The historical epoch, the visual culture, the gender and age of the visualized face, but above all the pragmatic purpose of the facial display determine whether the picture of a face will be scrutinized for resemblance or whether, on the contrary, will be tolerated no matter what the degree of idealization. At one end of the spectrum, facial pictures with the minimum degree of idealization are predominant. Such is the case of facial images that are used for administrative and bureaucratic purposes, by state archives and facial recognition software. Most visa application requirements, for instance, impose that facial pictures avoid any possible idealization feature, including tilting or smiling, for the sake of maximum resemblance with a supposed original. An ideology of facial normativity introduces itself in the implementation of these requirements: the fact that the zero degree of a face is considered to be its serious, non-smiling version facilitates automatic face recognition but, at the same time, reveals the expectations of the state as regards the citizens' reverent attitude toward its bureaucracy (Fig. 15).

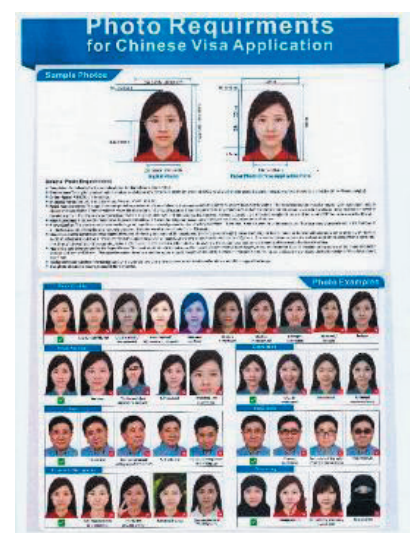

Fig. 15: 2018 China requirements for face photograph in visa applications. 
Passport pictures, however, are not meant to seduce. They must just convince about their resemblance. At the other end of the spectrum, facial pictures that people post on dating social networks follow, on the contrary, completely different strategies, with much higher degrees of idealization and, sometimes, involuntary or even intentional effects of unlikeliness. Future research will have to investigate the digital iconography of the face in order to understand, on the one hand, what historical, sociocultural, and stylistic agencies contribute to determine a specific alteration trend in the representation of the face for seductive purposes and, on the other hand, how the circulation of this digital iconography impacts on the everyday offline displaying of the face and its signification. If digital 'daters' are less and less preoccupied that their online facial images resemble the offline ones, some trends and practices might develop so as to transform the latter in conformity with the former. Or else, exactly as the present-day media system is being characterized by increasing tolerance towards fake news, so future digital dating frameworks might become more and more resilient as regards 'fake faces', especially for offline encounters might become a secondary or even an unwished consequence of online flirting.

Investigation in this field entails major problems of n-ethnography and privacy, which cannot be discussed here. The first task that semiotics will have to carry on, however, will be that of developing a typology of digital dating faces, articulating the main lines of visual rhetoric through which current users seek to attract, retain, and manipulate the attention of their interlocutors while building for themselves, at the same time, a digital self-perception and self-imaginary of their faces. Researching the representation of the face in digital environments, indeed, might become in the future one of the main gates to access the most central dynamics in the development of human symbolical interaction in the era of its digital reproduction. Will the human face lose its aura, exactly like artworks did as a result of their mechanical reproduction, as Walter Benjamin first intuited? There is no shortcut: semiotics will have to deal with this philosophical question through both quantitative and qualitative analysis of 'facial big data'. 


\section{References}

Ayalon, Liat and Ateret Gewirtz-Meydan. 2017. “Senior, Mature or Single: A Qualitative Analysis of Homepage Advertisements of Dating Sites for Older Adults", 876. Computers in Human Behavior, 75 (October) (Elsevier).

Blacka, Erik, Kelsey Mezzinab, and Lindsay Thompsona. 2016. "Anonymous Social Media: Understanding the Content and Context of Yik Yak", 17-22. Computers in Human Behavior, 57 (April 1) (Elsevier).

Danesi, Marcel. 2016. The Semiotics of Emoji: The Rise of Visual Language in the Age of the Internet. New York, NY: Bloomsbury Academic [Bloomsbury Advances in Semiotics].

Dixson, Alan F. 2012. Primate Sexuality: Comparative Studies of the Prosimians, Monkeys, Apes and Human Beings. Oxford, UK: Oxford University Press.

Duguay, Stefanie. 2017. "Dressing up Tinderella: Interrogating Authenticity Claims on the Mobile Dating App Tinder", 351-67. Information, Communication \& Society, 20, 3 (March) (Taylor \& Francis).

Ellison, Kirsten L. 2014. "Age Transcended: A Semiotic and Rhetorical Analysis of the Discourse of Agelessness in North American Anti-Aging Skin Care Advertisements", 20-31. Journal of Aging Studies, 29 (April) (Elsevier).

Glazer, Trip. 2017. “The Semiotics of Emotional Expression”, 189-215. Transactions of the Charles S. Peirce Society, 53, 2 (Spring) (Indiana University Press).

Graziano, Michael. 2009. The Intelligent Movement Machine: An Ethological Perspective on the Primate Motor System. Oxford, UK: Oxford University Press.

Birdwhistell, Ray L. 1971. "Kinesics: Inter- and Intra-Channel Communication Research", 527-48. In Kristeva, Julia, Josette Rey-Debove, and Donna Jean Umiker, eds. 1971. Essays in Semiotics / Essays de sémiotique. Paris and The Hague: Mouton De Gruyter.

Branco, Patricia, Massimo Leone, and Richard Mohr. 2018. Tools of Meaning: Representation, Objects, and Agency in the Technologies of Law and Religion, ["I saggi di Lexia" 29]. Rome: Aracne.

Johnson, Kristine, Marilena O. Vilceanu, and Manuel Pontes. 2017. “Use of Online Dating Websites and Dating Apps: Findings and Implications for LGB Populations", 60-66. Journal of Marketing Development and Competitiveness, 11, 3 (October). (North American Business Press). 
Kushlev, Kostadin, et al. 2019. "Smartphones Reduce Smiles between Strangers”, 12-16. Computers in Human Behavior, February, 91 (Elsevier).

Leone, Massimo. 2016. "Nature and Culture in Visual Communication: Japanese Variations on Ludus Naturae”, 213-245. Semiotica, 213.

Leone, Massimo. 2017. "Socio-sémiotique des « livres à visages »", online. In Eric Landowski, ed. 2017. Sémiotique et engagement. Monographic issue of Nouveaux Actes Sémiotiques (Journal of the French Association for Semiotic Studies), 120; available at http://epublications.unilim.fr/revues/as/5816 (last accessed 4 October 2018).

Mathé, Anthony. 2010. "Sémiotique des apparences corporelles. Textes, images et pratiques de mode et de beauté dans la société française (20042008)". PhD Dissertation, Centre de Recherches Sémiotiques (CeReS), University of Limoges, France.

Morris, Desmond. 1962. The Biology of Art: A Study of the Picture-Making Behaviour of the Great Apes and its Relationship to Human Art. New York, NY: Knopf.

Ogilvie, Madeleine. 2005. The Semiotics of Visible Face Make-Up: The Masks Women Wear. PhD Dissertation, School Of Marketing, Tourism And Leisure. Edith Cowan University, Australia.

Petitot, Marie. 2015. "La mode des mouches, attributs de la féminité", online. In Plume d'histoire, 20 September. Available at http://plume-dhistoire.fr/mode-mouches-attributs-feminite/ (last accessed 5 October 2018).

Quiquempois, Olivier, ed. 2014. Corps paré, corps transformé : la peau comme support d'expression = Made Up Bodies, Transformed Bodies: Skin as Surface of Expression. Cinisello Balsamo, Milan: Silvana.

Sotoudeh, Ramina, Roger Friedland, and Janet Afary. 2017. "Digital Romance: The Sources of Online Love in the Muslim World", 429-39. Media, Culture \& Society, 39, 3 (April) (SAGE Journals).

Stevenson, Ian. 1997. Reincarnation and Biology: A Contribution to the Etiology of Birthmarks and Birth Defects, 2 vols. Westport, CN: Praeger.

Stewart, Susan (Susan Margaret). 2017. Painted Faces: A Colourful History of Cosmetics. Stroud, Gloucestershire : Amberley Publishing.

Tang, Denise Tse-Shang. 2017. "All I Get is an Emoji: Dating on Lesbian Mobile Phone App Butterfly", 816-32. Media, Culture \& Society, 39, 6 (September) (SAGE Journals). 
Toma, Catalina L. 2017. "Developing Online Deception Literacy While Looking for Love", 423-8. Media, Culture \& Society, 39, 3 (April) (SAGE Journals).

Trumble, Angus. 2004. A Brief History of the Smile. New York, NY: BasicBooks.

Van Leeuwen, Edwin J.C., Katherine A. Cronin, and Daniel B. M. Haun. 2014. "A Group-Specific Arbitrary Tradition in Chimpanzees (Pan Troglodytes)", 1421-5. Animal Cognition, 17, 6 (November). (Springer).

Van Ouytsel, Joris et al. 2017. "Sexting: Adolescents' Perceptions of the Applications Used for, Motives for, and Consequences of Sexting", 446-70. Journal of Youth Studies, 20, 4 (May) (Taylor \& Francis).

Vasey, George. 1877. The Philosophy of Laughter and Smiling. 2nd ed., enl. and improved. London: J. Burns.

Xue, Minhui et al. 2017. "Characterizing User Behaviors in Location-Based Find-and-Flirt Services: Anonymity and Demographics: A WeChat Case Study", 357-67. Peer-to-Peer Networking and Applications, 10, 2 (March) (Springer).

Wang, Li and Pertti Alasuutari. 2017. "Co-Construction of the Tourist Experience in Social Networking Sites: Two Forms of Authenticity Intertwined", 388-405. Tourist Studies, 17, 4 (December) (SAGE Journals).

Ward, Janelle. 2017. "What are you Doing on Tinder? Impression Management on a Matchmaking Mobile App", 1644-59. Information, Communication \& Society, 20, 11 (November) (Taylor \& Francis).

Wende, Waltraud (aka "Wara"), ed. 2008. Wie die Welt lacht: Lachkulturen im Vergleich. Würzburg: Königshausen \& Neumann. 